\title{
Faculty Use of Author Identifiers and Researcher Networking Tools
}

\author{
Clara Y. Tran and Jennifer A. Lyon
}

This cross-sectional survey focused on faculty use and knowledge of author identifiers and researcher networking systems, and professional use of social media, at a large state university. Results from 296 completed faculty surveys representing all disciplines (9.3\% response rate) show low levels of awareness and variable resource preferences. The most utilized author identifier was ORCID while ResearchGate, Linkedln, and Google Scholar were the top profiling systems. Faculty also reported some professional use of social media platforms. The survey data will be utilized to improve library services and develop intra-institutional collaborations in scholarly communication, research networking, and research impact.

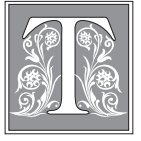

echnology has advanced at a remarkable speed for decades. However, scholarly publishing has not kept up with the rate of technological change for the past two decades, and traditional publishing models continue to prevail. ${ }^{1}$ Although new scholarly communication methods such as open access and digital repositories have been evolving, there is no well-established and universally accepted communication model that can "define merit and provide rewards" for researchers. ${ }^{2}$ This is exacerbated by the lack of necessary tools and services that enhance proper author identification for a scholar's output. ${ }^{3}$

The rapid growth and development of researcher networking systems and social networking platforms plays an important role in improving the connection of researchers academically and socially. Researcher- or faculty-specific networking systems usually provide a professional profile to which the scholar can upload and display publication data, research interests, and educational and employment data. Some of these systems, occasionally nicknamed "Facebook for scientists," allow researchers to share knowledge, discuss shared interests, and comment on or criticize published work. ${ }^{4}$ Additionally, some "general" social networking platforms can serve as a vehicle for sharing work and/or networking with professional colleagues. These may include Facebook, Twitter, Google+, MySpace, Pinterest, Tumblr, and MeetUp.

In recent years, most, if not all, academic research institutions have been developing and promoting faculty profiling systems designed to fulfill a variety of purposes including departmental websites, faculty tenure and promotion systems, administrative reporting, credentialing, and facilitating research collaboration across disciplines. Such systems include VIVO, Harvard Profiles, SciVal, and many unique internally

Clara Y. Tran is Science Librarian in the Science and Engineering Library, and Jennifer A. Lyon is Biomedical and Translational Research Librarian in the Health Sciences Library, at Stony Brook University; e-mail: Yuet.tran@stonybrook.edu, Jennifer.a.lyon@stonybrook.edu. (2017 Clara Y. Tran and Jennifer A. Lyon, Attribution-NonCommercial (http://creativecommons.org/licenses/by-nc/4.0/) CC BY-NC. 
developed institutional programs. Additionally, there has been an expansion of alternative, external, web-based researcher networking sites including ResearchGate, LinkedIn, Google Scholar, and others. This has led to inconsistent use of these systems by individual faculty and created a difficulty for institution administrators attempting to choose, implement, and gain faculty acceptance of a specific system. Further, many of the web-based resources are commercial operations, which limits the ability of institutions to draw upon the stored profile information freely. ${ }^{5}$

One of the challenges for tracking scholars' publications is name ambiguity. In recent years, scholarly productivity has grown tremendously, making it difficult to distinguish who the author of a particular document may be due to identical or similar names, name changes over time, the use of aliases, or writing as "anonymous." ${ }^{6}$ This fundamental problem of name ambiguity has been extensively discussed in the literature, as it causes multiple problems such as creating metadata in a repository system ${ }^{7}$ and tracking authors in the publishing world. As in the case of Journal of Applied Polymer Science, "J. Zhang" was "the most prolific author" in 2012, which actually represented multiple, indistinguishable authors. ${ }^{8}$ A Nature article reported that China's Ministry of Public Security estimates that 1.1 billion people, that is, roughly 85 percent of China's population, share just 129 surnames. $^{9}$

An author identifier is a unique "symbol" for an author that can be used to distinguish that person's work from all others, regardless of any similarities of name, institution, or discipline. Recently, organizations and publishers have been developing tools and author registration systems to assist scholars in tracking their publications and receiving recognition for their works. Early examples such as arXiv and Research Papers in Economics (RePEc) have already included author identification services in their article repositories. ${ }^{10}$ Further, ResearcherID (Thomson Reuters) and Scopus Author Identifier (Elsevier) are efforts by major bibliographic database providers to assign a unique researcher identification to their bibliographic records. ${ }^{11}$ Each of these, in its own fashion, requires authors to register for an author identifier and/or check and verify an "automated" author profile, through which they can identify and track their publications. One downside to these attempts at author identification is that they only function for publications indexed in the database(s) belonging to the specific commercial database provider. Therefore, there has been a significant need for an open, noncommercial, online mechanism to provide authors with a unique identifier that can be applied to their publications. An increasingly successful project for meeting this need is the Open Researcher \& Contributor ID (ORCID), which was launched in October 2012. ${ }^{12}$

Researchers tend to be cautious of discussing their papers, sharing data, and making comments on social platforms, whether to protect new discoveries or personal privacy. Therefore, they often prefer to use their own communication channels instead of more public networking platforms. ${ }^{13}$ Also, faculty members vary widely in their technological and Internet skills and are idiosyncratic in their choices and awareness of author identifiers, social media platforms, and online professional networking systems. Therefore, it is important to understand the existing state of faculty awareness of, interest in, and usage of these systems both for improved training and services and for encouraging acceptance of a single university-mandated option. This study was designed to sample the present viewpoint of faculty at Stony Brook University.

\section{Methods}

A major research and academic center within the State University of New York (SUNY) system, Stony Brook University (SBU) is located on Long Island approximately 60 miles east of New York City. With a student population of approximately 25,000, SBU offers programs from multiple academic disciplines, including the Colleges of Arts \& Sciences, 
Business, Engineering \& Applied Sciences, and the Schools of Dental Medicine, Health Technology \& Management, Journalism, Marine \& Atmospheric Sciences, Medicine, Nursing, Professional Development, and Social Welfare.

An online survey was developed in Qualtrics consisting of a total of nine questions addressing faculty knowledge and use of author IDs, researcher networking tools, and social media. All survey responses were kept anonymous, with only employment status and major academic division collected as demographic data. To pretest for comprehension, completion time, and question formatting, all library faculty were invited to complete the preliminary version of the survey and make suggestions. Based on the received feedback, the survey was revised before final distribution to all SBU faculty.

The survey was disseminated through various media during the month of April 2015, including all-faculty e-mails (April 13 and 24), the SBU Libraries' websites, weekly campus announcements (April 6 and 13), and "hand-out" bookmarks at all library circulation desks. Additionally, individual library faculty advertised the survey to their specific liaison departments to encourage participation.

\section{Results}

Of SBU's 3,433 faculty, 300 completed the survey and 18 provided incomplete responses, resulting in a 9.3 percent response rate from faculty. Additionally, because of the widespread advertising of the survey, 27 other SBU personnel also completed the survey: administrative, clinical, and research staff $(n=10,2.8 \%)$; graduate students $(\mathrm{n}=6,1.7 \%)$; and postdocs $(\mathrm{n}=10,2.8 \%)$.

Of the 328 answering the question regarding discipline, the largest number of responses came from the Health Sciences $(n=87,27 \%)$, followed by Physical Science $(n=49,15 \%)$, Biological Science $(n=48,15 \%)$, Arts \& Humanities $(n=44,13 \%)$, Social Sci-

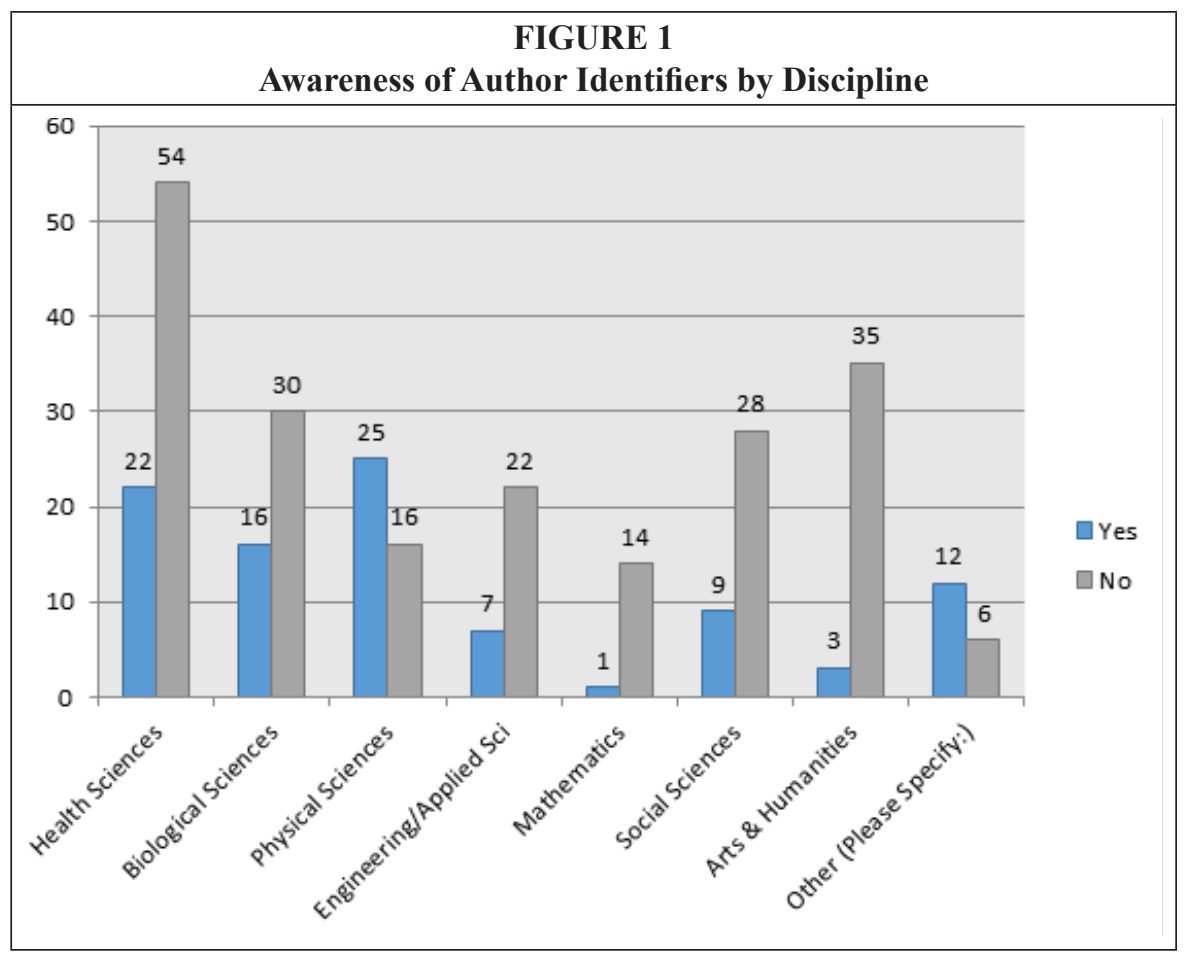


ences $(n=38,12 \%)$, Engineering and Applied Science $(n=31,9 \%)$, Mathematics $(n=15$, $5 \%)$, Marine Science $(n=6,2 \%)$, and others $(n=8,2.4 \%)$. The others included business $(n=3)$, professional development $(n=4)$, and library $(n=1)$ faculty.

\section{Awareness of Author Identifiers}

Overall, 32 percent ( $n=95)$ of 300 responders expressed familiarity with the idea of author identifiers used to distinguish publications. Interestingly, the Physical Sciences faculty demonstrated a dramatically higher percentage of familiarity at 61 percent, compared to Biological Sciences (35\%), Health Sciences (29\%), and Social Sciences \& Engineering (24\% each). The lowest recognition was found in the Arts \& Humanities $(8 \%)$ and Mathematics (7\%). This is despite the Physical Sciences having only 41 responses compared, for example, to 76 in the Health Sciences, 46 in the Biological Sciences, and 38 in Arts \& Humanities. Therefore, the high preponderance of recognition in the Physical Sciences is not due to a higher response rate (see figure 1).

\section{Awareness of Networking Systems}

A total of 299 faculty answered this question with, overall, 56 percent $(n=167)$ responding that they used a researcher or academic networking or profiling site. The breakdown by discipline is displayed in figure 2. The largest percentage of positive answers came from Social Sciences (69\%), followed by Engineering (66\%), Biological Sciences (59\%), Arts \& Humanities (58\%), Health Sciences and Physical Sciences (51\% each), and Mathematics (27\%). However, the actual number of responses was higher from the Health Sciences $(n=76)$ which is representative of the higher number of Health Sciences faculty who responded to the survey in total. Only 36 Social Sciences and 29 Engineering faculty responded to the question, but those who did had higher preponderance of usage of these systems compared to the Health, Biological, and Physical Sciences.

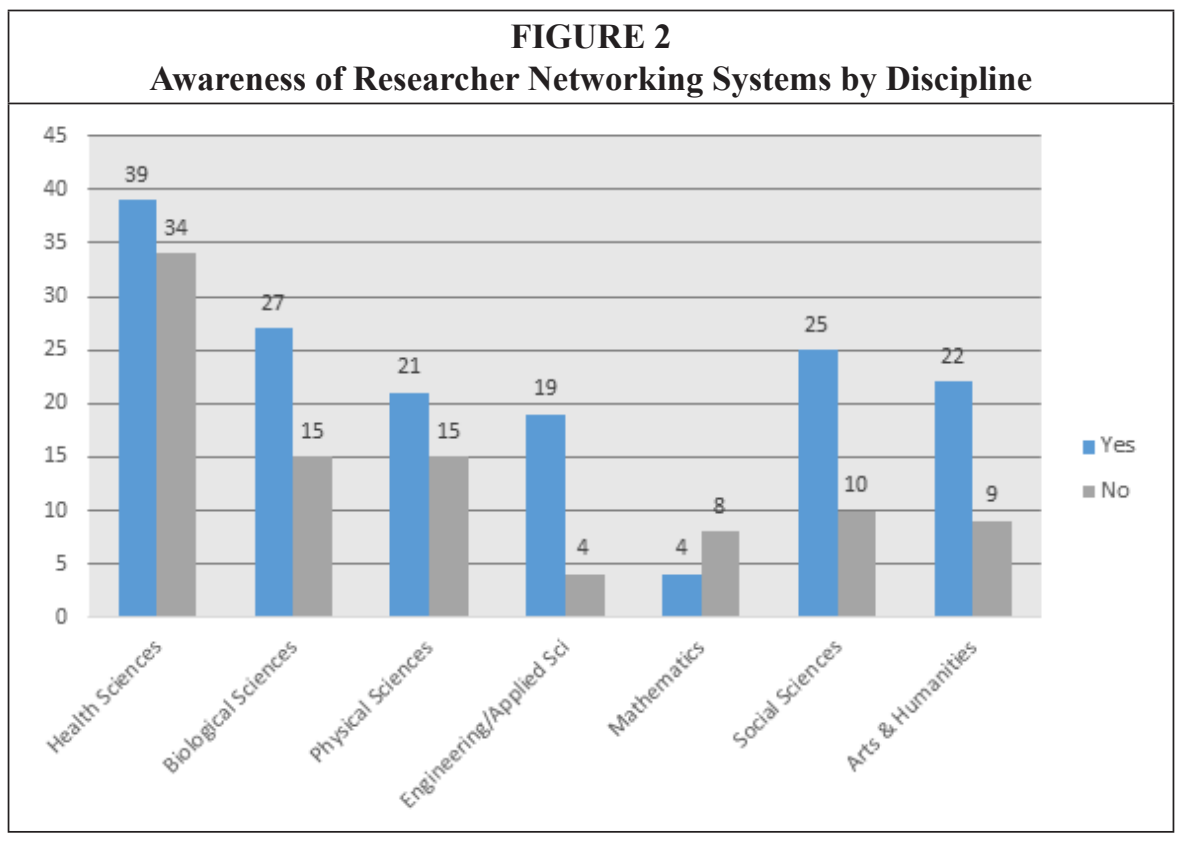




\section{Actual Use of Author IDs}

The majority of the 335 respondents, not surprisingly, indicated no use of author identifiers (59\%, n=198). For those faculty who used an author ID, the ORCID was the top response at 15 percent $(n=49)$. This was followed by the Scopus author ID $(9 \%, n=29)$, Thomson Reuters' Researcher ID (7\%, $n=25)$, and arXiv ID $(6 \%, n=20)$. Other faculty demonstrated confusion on what an author identifier was, offering alternative answers such as PubMed $(n=3)$ and Google Scholar $(n=4)$, neither of which provide an actual author identifier (see figure 3 ).

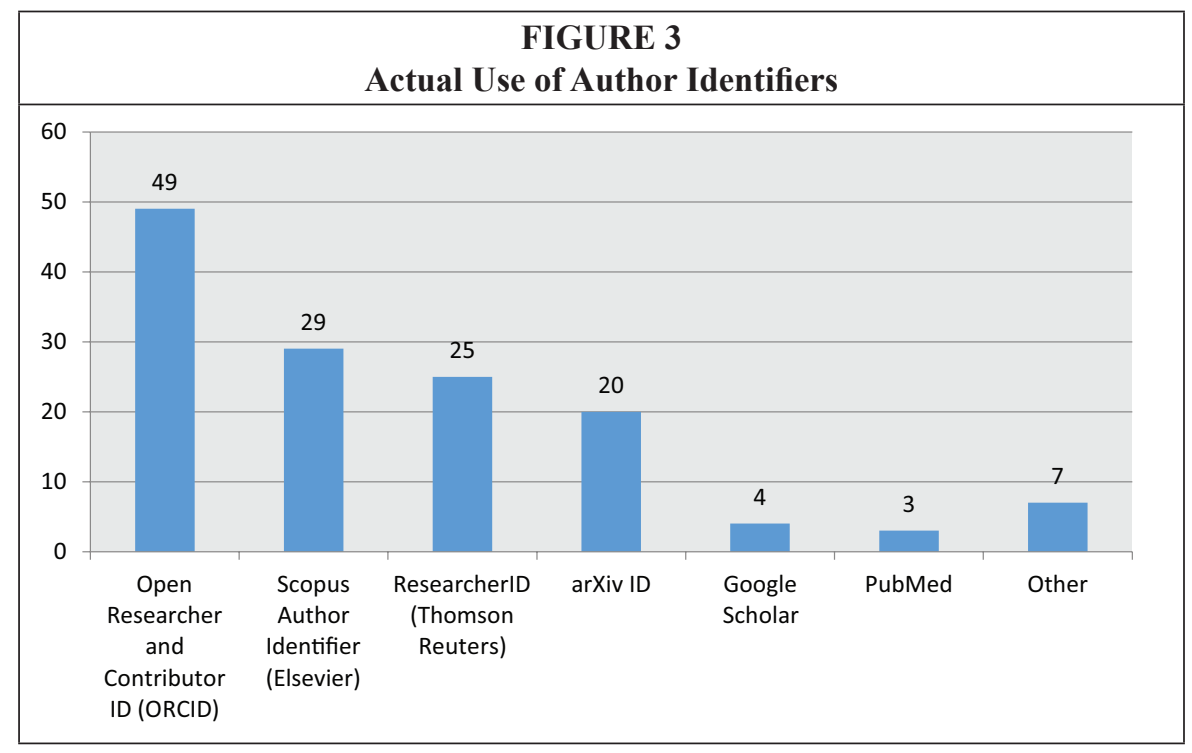

All disciplines except mathematics indicated some current use of ORCID, ResearcherID, and/or Scopus ID. Among these three identifiers, ORCID was the most preferred among all nonmathematics disciplines, particularly among faculty in the Health Sciences $(n=16)$. Alternatively, mathematicians showed a slight preference for arXiv ID ( $n=3$ compared to $n=0$ for the other identifiers). The Researcher ID was most used by Physical Sciences $(n=10)$ but was not used by either Mathematics or Arts \& Humanities. The Scopus author ID was most used in the Health Sciences $(n=9)$ but had some usage in all disciplines except mathematics.

\section{Actual Use of Networking Systems}

There was a variety of networking systems used by SBU faculty. The most commonly used by the 348 responders were ResearchGate ( $n=105,64 \%)$, LinkedIn ( $n=91,55 \%)$, Google Scholar ( $n=88,54 \%)$, and Academia.edu ( $n=40,24 \%)$. Three mentioned Microsoft Academic Search, and there were single mentions of VIVO and Harvard Profiles. Four reported use of "other institutional profiling systems," and 13 responded "other." These others included a wide range of responses, some demonstrating a misunderstanding of the question as they included their own personal webpages, scholarly publishers, GitHub, and PubMed. One responder indicated having LinkedIn and ResearchGate profiles but did not use them.

Failure of understanding the concept of a "profiling" or "networking" system was also demonstrated by the comparison of the results of this question with the earlier question asking more generally "do you use a networking/profiling system." The 
total responses to the question specifying named systems numbered 348 but only 299 responded to the more general question. Also, only 2 responded "none" to the specific question, compared to 102 reporting "no" in response to the general question. Therefore, they respond better to being asked about specific systems by name than to the concept of "researcher networking systems" itself (see figure 4).

As described above, ResearchGate, LinkedIn, and Google Scholar were the most used tool across all disciplines; this holds true when the data are broken out by academic discipline. For the Health Sciences (overall the largest group of responses, $\mathrm{n}=77$ ), ResearchGate was noticeably the favored option, with 32 uses compared to 15 for Google Scholar and 21 for LinkedIn. In the Biological Sciences $(n=60)$, ResearchGate and LinkedIn were approximately equivalent, with 20 and 19 uses respectively, while Google Scholar had 14. On the other hand, for the Social Sciences, ResearchGate and Google Scholar had equivalent usage, with 14 and 13 uses each, while LinkedIn was slightly lower at 11. Similarly, for Engineering and Applied Sciences, LinkedIn was the lowest of the top three platforms $(n=11)$. However, Engineering differed in that Google Scholar took the top spot with 19 uses compared to 13 for ResearchGate. Perhaps because of its focus on scientific research, ResearchGate $(n=5)$ was not used much by Arts \& Humanities $(n=47)$; those faculty showed a preference for LinkedIn $(n=13)$ and Google Scholar $(n=10)$. The Physical Sciences faculty $(n=30)$ were approximately equivalent in their use of all three of these platforms (Google, $n=10$; ResearchGate, $n=10$; LinkedIn, $n=8)$. Mathematics faculty $(n=5)$ reported very little use of any of these tools, the majority of whom $(n=3)$ selected ResearchGate. There was only rare and sporadic choice of other platform options.

\section{Actual Use of Social Media}

Of 333 responses received on the question regarding professional use of social media platforms, only 150 (45\%) indicated such use. Those who did demonstrated a

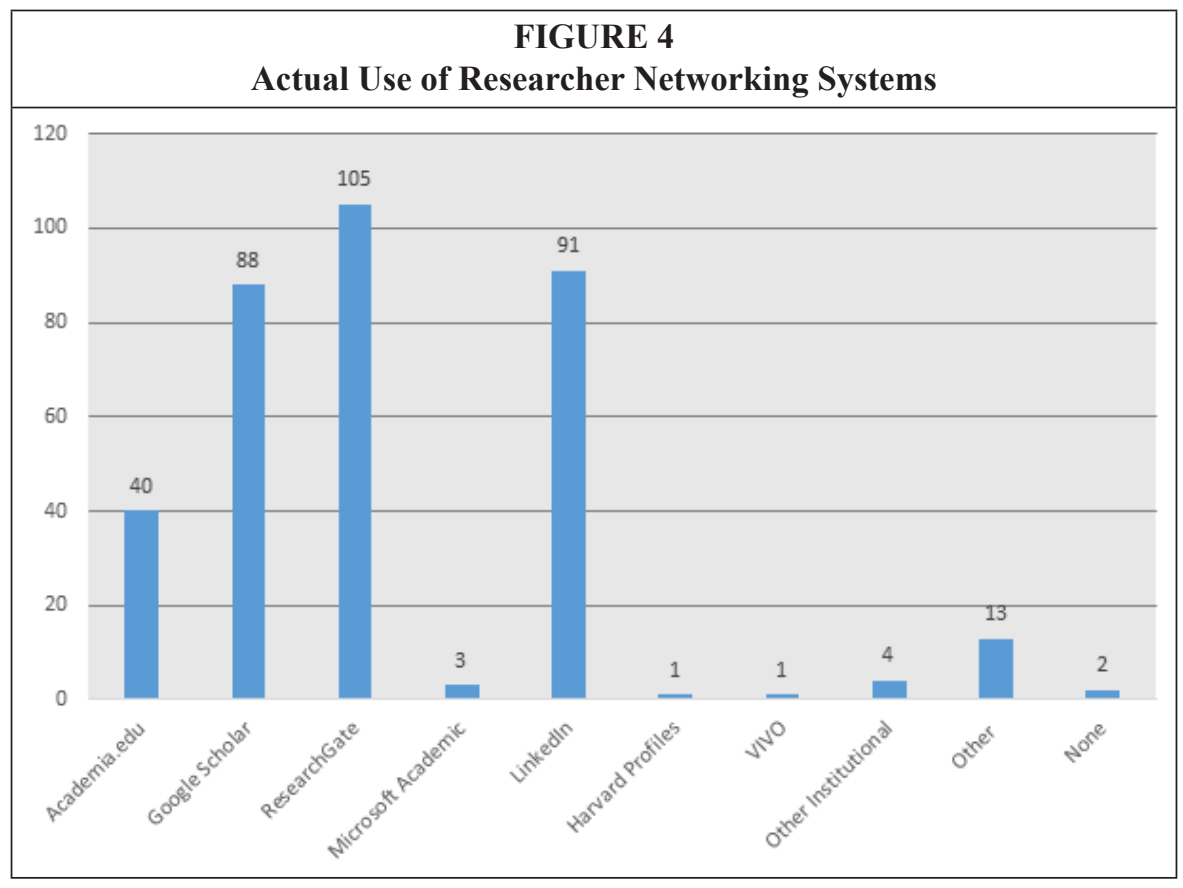


wide range of individual choices that also overlapped with researcher networking systems. This shows that the line between "professional" and "social" networking sites is not always clear. For example, ResearchGate $(n=2)$, Academia.edu $(n=1)$, and LinkedIn $(n=15)$ were provided as answers to this question. However, quite a few "traditionally social" platforms were also selected. These included Facebook $(n=61$, $41 \%)$, Twitter $(n=38,25 \%)$, Google Sites/Scholar $(n=22,15 \%)$, Pinterest $(n=1,1 \%)$, YouTube $(n=2,1 \%)$, Meetup $(n=4,3 \%)$, Instagram $(n=1,1 \%)$, and Goodreads $(n=1$, $1 \%$ ). The use of social media for professional purposes is an intriguing trend today, and these results show the spread of use of such platforms by university faculty and researchers (see figure 5).

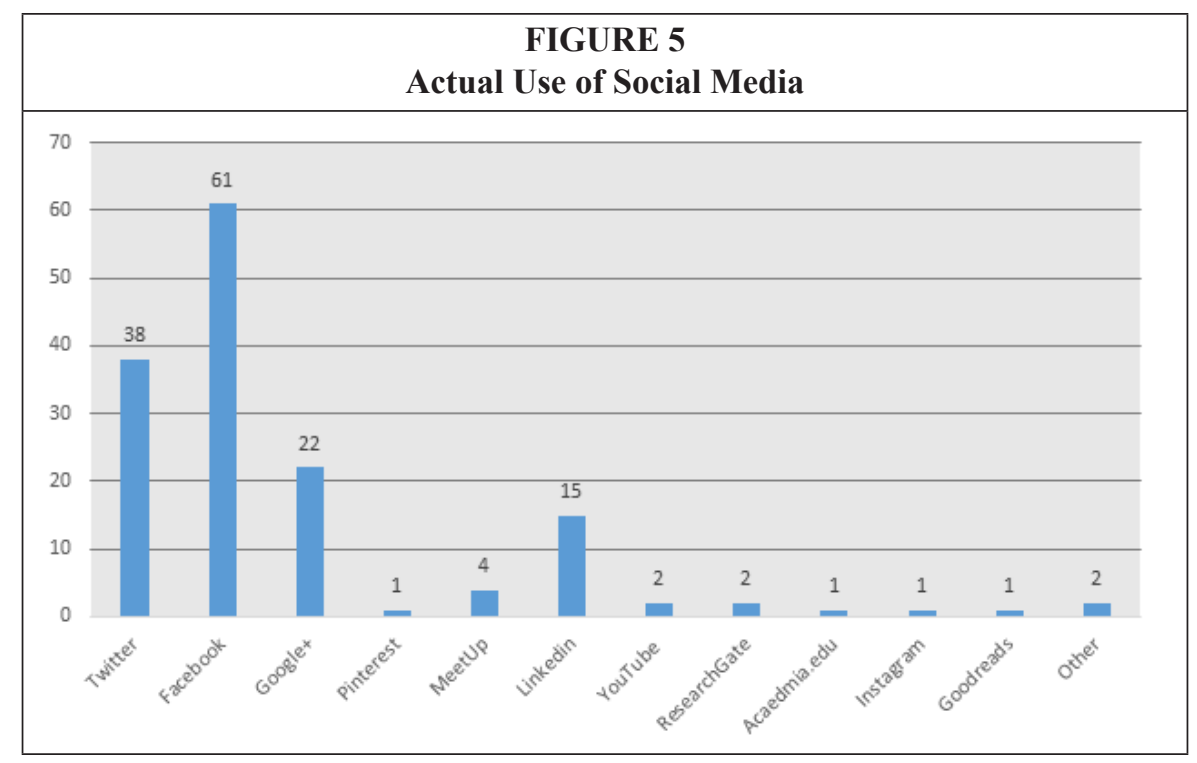

Consistent with the overall data, Twitter and Facebook remained the most used tool across all disciplines. Interestingly, Facebook had the highest percent usage among responding faculty in the Arts \& Humanities $(n=38 \%)$ and the Social Sciences $(n=21 \%)$. The next highest percentage for Facebook was in the Health Sciences at 14 percent, with Biological Sciences, Physical Sciences and Engineering at 13 percent. For Twitter, Arts \& Humanities ( $n=18 \%$ ) and Social Sciences $(n=17 \%)$ also had the highest percent usage among respondents. Interestingly, the Health Sciences and Engineering had a markedly lower percent usage $(n=7 \%)$ of Twitter in comparison, while Biological and Physical Sciences were in the middle at 13 percent each. Mathematics faculty did not report any use of social media at all.

Additionally, 133 of 290 respondents (46\%) stated that they maintain their own professional website or blog. The ease of use of blogging and personal website development platforms is clearly being taken advantage of by faculty instead of relying solely on the institution to create and maintain such sites.

\section{Levels of Interest in Use and Training for both Author IDs and Networking Systems}

Faculty were asked to respond to a 5-point Likert Scale from Strongly Agree (5) to Strongly Disagree (1) on questions relating to their interest in creating author IDs \& research profiles and training. Full results are reported in table 1. 
TABLE 1

Levels of Interest in Use and Training for both Author IDs and Networking Systems

\begin{tabular}{|l|c|c|c|c|c|c|c|}
\hline Question & $\begin{array}{c}\text { Strongly } \\
\text { Agree }\end{array}$ & Agree & Neither & Disagree & $\begin{array}{c}\text { Strongly } \\
\text { Disagree }\end{array}$ & $\begin{array}{c}\text { Total } \\
\text { Responses }\end{array}$ & $\begin{array}{c}\text { Mean } \\
\text { Score }\end{array}$ \\
\hline Author Identifiers & & 102 & 107 & 10 & 10 & 293 & 3.68 \\
\hline $\begin{array}{l}\text { Having a unique } \\
\text { author identifier } \\
\text { associated with } \\
\text { my publications } \\
\text { is valuable. }\end{array}$ & 64 & 59 & 83 & 79 & 48 & 293 & 2.77 \\
\hline $\begin{array}{l}\text { I would be } \\
\text { interested in } \\
\text { attending a } \\
\text { workshop on } \\
\text { how to create an } \\
\text { author identifier. }\end{array}$ & 24 & 134 & 77 & 20 & 15 & 293 & 3.61 \\
\hline $\begin{array}{l}\text { I would use an } \\
\text { online guide to } \\
\text { creating an author } \\
\text { identifier. }\end{array}$ & 47 & 104 & 107 & 27 & 21 & 291 & 3.34 \\
\hline $\begin{array}{l}\text { I am interested } \\
\text { in registering an } \\
\text { author identifier. }\end{array}$ & 32 & 104 & & & & & \\
\hline
\end{tabular}

\begin{tabular}{|l|c|c|c|c|c|c|c|}
\hline \multicolumn{2}{|l|}{ Researcher Networking Systems } & 113 & 64 & 7 & 8 & 291 & 3.99 \\
\hline $\begin{array}{l}\text { Having a } \\
\text { research/ } \\
\text { academic profile } \\
\text { including my } \\
\text { publications is } \\
\text { valuable. }\end{array}$ & 99 & 74 & 84 & 73 & 32 & 287 & 2.95 \\
\hline $\begin{array}{l}\text { I would be } \\
\text { interested in } \\
\text { attending a } \\
\text { workshop on how } \\
\text { to create a profile. }\end{array}$ & 24 & 112 & 86 & 31 & 17 & 287 & 3.45 \\
\hline $\begin{array}{l}\text { I would use an } \\
\text { online guide to } \\
\text { creating a profile. }\end{array}$ & 41 & 107 & 103 & 24 & 15 & 284 & 3.43 \\
\hline $\begin{array}{l}\text { I am interested in } \\
\text { creating a profile. }\end{array}$ & 35 & 86 & 92 & 32 & 27 & 289 & 3.36 \\
\hline $\begin{array}{l}\text { I am interested in } \\
\text { having a profile } \\
\text { created for me } \\
\text { by Stony Brook } \\
\text { University. }\end{array}$ & 52 & & & & & & \\
\hline
\end{tabular}


More than half (57\%) selected Strongly Agree (SA) or Agree (A) in response to the statement "Having a unique author identifier associated with my publications is valuable" (mean 3.68; 166/293; 57\% SA/A). Similarly, 47 percent expressed interest in personally registering an author ID (mean 3.34; 136/291 SA/A). The responses to questions regarding training preferences indicated clearly that faculty prefer access to an online guide (mean 3.61; 181/293; 62\% SA/A) to an in-person workshop (mean $2.77 ; 83 / 293 ; 28 \% \mathrm{SA} / \mathrm{A}$ ). However, despite that low percentage of interest in an inperson workshop, the raw numbers show that 83 individual faculty stated they were interested in such a workshop.

Regarding research networking profiles, the results were similar, but with higher raw numbers and percentages across all questions. In response to the statement "Having a research/academic profile including my publications is valuable," 73 percent (mean $3.99 ; 212 / 291$ ) selected SA/A. Again, the faculty preferred access to an online guide to an in-person workshop; even so, there were 98 individual positive responses to the question on interest in such a workshop. Approximately half of the faculty were interested in creating their own profile (mean $3.43 ; 142 / 284 ; 50 \%$ SA/A) or in having an institution-created profile (mean $3.36 ; 138 / 289 ; 48 \%$ ).

\section{Discussion}

Our survey results show that there is recognition and use of existing Author ID and researcher networking profiles, as well as some professional use of online social media platforms among academic faculty across all disciplines. Additionally, there was notable interest in access to training and support on the same resources. At this time, ORCID appears to have gained the highest level of awareness and use among Stony Brook faculty. Faculty also reported use of the two most well-known commercial authorIDs: Thomson Reuters' ResearcherID and Elsevier's Scopus Author ID. There was even more interest among faculty in having an online platform on which they could collect and display their work and network both professionally and socially with their colleagues. Unsurprisingly, there was notable variation in the choice of tools, with ResearchGate, LinkedIn, and Google Scholar among the most highly used. Similarly, the growing societal trend toward widespread use of social media for all purposes, including scholarly communication and research impact, is represented in our results. As Stony Brook is still in the process of developing its own faculty profiling system and has only just begun using Yammer as an institution-wide forum for communication within the last couple of months, there may be significant changes ahead.

Based on the survey results, ORCID was selected as the first target of the Stony Brook Libraries for marketing and training. ORCID is an open and international nonprofit organization ${ }^{14}$ that provides a sustainable registry of reliable and "persistent unique identifiers for researchers and scholars."15 Scholars self-claim their biographic and bibliographic information in a uniquely identified profile containing biographic, employment, education, grant, and publication information. Once established, universities, funding organizations, and publishers can use this information without limitations. ${ }^{16}$ Permanent and solely owned by the scholar, it is portable: a vital quality that allows the researcher to carry it with him or her when moving to new institutions and is easily reusable by those institutions. While ORCID does not provide the social functionality of online networking and social interaction platforms, it allows researchers to connect its profile to other systems, including Scopus, RePEc, ResearcherID, and VIVO, as well as to grant and manuscript submission systems. ${ }^{17}$ ORCID is presently the only external source from which data can be pulled into the National Institutes of Health's SciENcv grant biosketch system. ${ }^{18}$ This linkage, in particular, is of very high value to scientists. 
There were differences among the disciplines in their resource preferences. For author identifiers, current use of ORCID, ResearcherID, and/or Scopus ID was observed in all disciplines except Mathematics, with the highest use of ORCID in the Health Sciences. Alternatively, the arXiv ID was used by Mathematicians, Engineers, and Physical Scientists but not by other disciplines, which makes sense given its subject focus. The Researcher ID was most used by Physical Sciences but was not used by either Mathematics or Arts \& Humanities. The Scopus author ID was most used in the Health Sciences but had some usage in all disciplines except Mathematics. For profiling systems, ResearchGate, LinkedIn, and Google Scholar were the most used tools across all disciplines with varying preferences for them between disciplines. ResearchGate was most highly used among Health and Biological Science faculty, but, perhaps because of its focus on scientific research, it was not used much by Arts \& Humanities, whose faculty showed a preference for LinkedIn and Google Scholar. Google Scholar had its highest popularity in the Social Sciences and Engineering and Applied Sciences, with some use across the board. Mathematics faculty reported very little use of any of these tools, but those who did selected ResearchGate. Arts \& Humanities and Social Sciences showed the highest use of social media professionally, regardless of number of responses overall, although all disciplines except mathematics reported some social media use.

Given the level of interest in online guides to the use of tools observed in the study results, the development of such resources is already underway. Further, the number of faculty interested in an in-person workshop on author IDs $(n=83)$ and researcher networking systems ( $n=98)$, assuming the 9 percent sample is representative of the faculty as a whole, strongly suggests that offering such workshops should be worthwhile. A library-based session introducing ORCID is being piloted by the Stony Brook University Libraries and will be marketed more heavily in upcoming semesters.

\section{Limitations}

We had a 9.3 percent overall response rate, with variable numbers of responses to each question. The large percentage of "don't know" responses is important, but it left us with smaller numbers for the questions dealing with actual use of resources. There was a necessity to balance the number of questions, and thus time required to complete the survey, with the ability to gain more detailed data. Survey research is also dependent upon the willingness of individuals to participate, and there may be some unknown differences between the responding sample and the full population; however, the wide range of disciplines represented within our sample and its size (nearly $10 \%$ ) suggests that it is, in fact, illustrative of the faculty as a whole.

\section{Future Research and Collaborations}

The results of this survey provide us with a beginning understanding of faculty behavior and attitudes at Stony Brook University, and there are possibilities for following up with more in-depth research including interviews and focus groups. One area that may be interesting to pursue is a study of the differences between disciplines in the choices of tools and social media platforms. Additionally, as we develop and market online and in-person training, the effect of these efforts can be tracked.

At present, one of the authors is serving as an advisor to teams at Stony Brook University that are testing and developing faculty profiling systems. Further, there has been some institutional discussion of implementing automatic ORCID registration for all faculty; however, this has yet to come to fruition. As Stony Brook has different information infrastructure and operations between the Health Sciences Center and the rest of campus, such implementation may face significant challenges. However, successful 
implementations have been documented in the literature for institutions such as the University of Hong Kong ${ }^{19}$ and the University of Michigan. ${ }^{20}$ Understanding the patterns of behavior, views, and needs of faculty and administrative stakeholders, combined with careful planning and good communications, will help overcome such hurdles.

Further, as librarians at many universities begin to address these issues, it may be fruitful to investigate their current practices and future plans. Understanding the efforts, successes, and failures among librarians in various settings could be valuable in identifying the best approaches for tracking author productivity and research impact, as well as enhancing opportunities for multidisciplinary research collaborations. Librarians can, and should, provide valuable expertise and support to faculty, administrators, and other relevant decision makers.

\section{Conclusion}

Our results provide an evidentiary basis for developing Stony Brook librarian training and support services relating to faculty use of author identifiers and networking systems. Librarians in academic settings are uniquely positioned to provide scholarly communication and research support services across their organization, as they connect to all aspects of the campus community. Therefore, librarians can lead campus-wide efforts to promote the use of ORCID and similar resources. This is equally true of the various researcher networking systems and social media platforms. Librarians are experts in collecting, annotating, weeding, and providing access to various information resources. Combining these skills with an understanding of faculty use and attitudes toward these resources allow librarians to help faculty navigate among the systems and select the most useful tools. As part of the process, librarians can create online tutorials and resource guides, in-person workshops, and individualized consultations to researchers showing them how to create profiles, add publications, and expand collaborations with researchers in their fields.

\section{Notes}

1. Michael Taylor, "The New Scholarly Universe: Are We There Yet?" Insights: The UKSG Journal 25, no. 1 (Mar. 2012): 12-17.

2. Ibid.

3. Ellen Rotenberg and Ann Kushmerick, "The Author Challenge: Identification of Self in the Scholarly Literature," Cataloging \& Classification Quarterly 49, no. 6 (Sept. 2011): 503-20.

4. Taylor, "The New Scholarly Universe: Are We There Yet?" 12-17.

5. Katie Fortney and Justin Gonder, "A Social Networking Site Is Not an Open Access Repository," available online at http://osc.universityofcalifornia.edu/2015/12/a-social-networking-siteis-not-an-open-access-repository/ [accessed 6 May 2016].

6. Linda Reijnhoudt, Rodrigo Costas, Ed Noyons, Katy Borner, and Andrea Scharnhorst, “'Seed Plus Expand': A General Methodology for Detecting Publication Oeuvres of Individual Researchers," Scientometrics 101, no. 2 (Nov. 2014): 1403-17.

7. Lizzy A. Walker and Michelle Armstrong, "'I Cannot Tell What the Dickens His Name Is': Name Disambiguation in Institutional Repositories," Journal of Librarianship \& Scholarly Communication 2, no. 2 (Mar. 2014): 1-10.

8. Stefano Tonzani, "Who Are You? ORCID Knows the Answer," Journal of Applied Polymer Science 128, no. 5 (June 2013): 2585.

9. William J. Thomas, Barbara Chen, and Gail Clement, "ORCID Identifiers: Planned and Potential Uses by Associations, Publishers, and Librarians," Serials Librarian 68, no. 1-4 (Jan. 2015): 332.

10. Todd Carpenter, "Working to Solve the Problems of Name Authority: The International Standard Name Identifier and Other Projects," Against the Grain: Linking Publishers, Vendors \& Librarians 21, no. 2 (Apr. 2009): 82-83.

11. Greg R. Notess, "Searching for Scholars," Online Searcher 37, no. 1 (Jan./Feb. 2013): 61-64.

12. Taylor, "The New Scholarly Universe: Are We There Yet?" 12-17. 
13. Richard Van Noorden, "Online Collaboration: Scientists and the Social Network," Nature 512, no. 7513 (Aug. 2014): 126-29.

14. ORCID, "ORCID: Connecting Research and Researchers," available online at http://orcid. org/ [accessed 18 December 2015].

15. Laurel L. Haak, "ORCID: Connecting Researchers and Scholars with Their Works," Insights: The UKSG Journal 26, no. 3 (Nov. 2013): 239-43; Laurel L. Haak, Martin Fenner, Laura Paglione, Ed Pentz, and Howard Ratner, "ORCID: A System to Uniquely Identify Researchers," Learned Publishing 25, no. 4 (Oct. 2012): 259-64.

16. Haak, Fenner, Paglione, Pentz, and Ratner, "ORCID: A System to Uniquely Identify Researchers," 259-64; Martin Fenner, Consol G. Gómez, and Gudmundur A. Thorisson, "Key Issue Collective Action for the Open Researcher \& Contributor ID (ORCID)," Serials 24, no. 3 (Nov. 2011): 277-79; Merle Rosenzweig and Anna Schnitzer, "An Initiative to Address Name Ambiguity," College \& Research Libraries News 76, no. 5 (May 2015): 260-64.

17. Haak, Fenner, Paglione, Pentz, and Ratner, “ORCID: A System to Uniquely Identify Researchers," 239-43.

18. National Center for Biotechnology Information, "SciENcv: Science Experts Network Curriculum Vitae," available online at www.ncbi.nlm.nih.gov/sciencv/ [accessed 18 December 2015].

19. David Palmer, "ORCID \& Its HKU Implementation," 2013 Meeting of the Pacific Rim Digital Library Alliance (PRDLA), available online at http://hdl.handle.net/10722/191175 [accessed 6 May 2016].

20. Rosenzweig and Schnitzer, "An Initiative to Address Name Ambiguity," 260-64. 